\title{
Participación femenina en el Movimiento Campesino de Santiago del Estero (Argentina). Reflexiones a partir de relatos de vida de integrantes "históricas"
}

\author{
Women's Participation in the Peasant Movement \\ of Santiago del Estero (Argentina). \\ Reflections from Life Stories of "Historical" Members
}

\author{
Mariela Pena* \\ Universidad de Buenos Aires/Conicet
}

\section{RESUMEN}

Este artículo examina el impacto de la participación en el Movimiento Campesino de Santiago del Estero-Vía Campesina (Mocase-VC), en el que las mujeres son sus integrantes "históricas". Se enmarca en los estudios de género y de las emociones en los movimientos sociales, y parte del trabajo etnográfico con familias campesinas y los relatos de vida de tres mujeres. Como producto de la creación de redes de solidaridad y de la experiencia colectiva en el movimiento, se sugiere el fortalecimiento femenino y cambios sustanciales en la autopercepción de los roles de género, que no han sido intencionalmente perseguidos. Las motivaciones iniciales se vinculan más al sentimiento de pertenencia a un colectivo de campesinos explotados y al anhelo de la participación política.

Palabras clave: mujeres campesinas en movimientos sociales, género, emociones, relato de vida.

\begin{abstract}
$\overline{\text { ABSTRACT }}$
This article examines the impact of the participation in the Movimiento Campesino de Santiago del Estero-Via Campesina (Mocase-VC) on women who are its "historical" members. It is informed by gender studies and studies of emotions in social movements, and is based on ethnographic work with peasant families and the life stories of three women. As a result of the creation of new solidarity networks and collective experiences, we suggest substantial changes in women's empowerment and selfperception of gender roles. However, these changes have not been intentionally pursued. Original motivations are more closely linked to the sense of belonging to a collective of exploited peasants.
\end{abstract}

Keywords: peasant women in social movements, gender, emotions, life story.

Doctora en Antropología de la Universidad de Buenos Aires. Becaria posdoctoral del Conicet y profesora de la Universidad de Lomas de Zamora. Su publicación más reciente es "Hacia una voz propia y feminista en el Movimiento Campesino de Santiago del Estero" (2017), en Revista Investigaciones Feministas 8 (1): 245-266. marielapena6@gmail.com 


\section{Introducción}

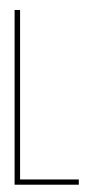

a conformación del Movimiento Campesino de Santiago del Estero (Mocase) de Argentina remonta sus orígenes formales a 1990, en la localidad santiagueña de Quilimí, como consecuencia de conflictos por la tenencia y propiedad de las tierras (Michi 2010). En una de las provincias argentinas signadas por uno de los índices más altos de pobreza, mayor cantidad de población rural y con tenencia precaria de la tierra, migraciones y deterioro del medio ambiente (Barbetta 2009), parte de esta población comienza a organizarse en lo que deviene un movimiento que transforma el conflicto por las tierras en un símbolo de disputas en torno al territorio, pero también de confrontación con el modelo de desarrollo, la propiedad privada y el capitalismo como modo de vida (Michi 2010). Barbetta (2009) sugiere que esta organización implicó “el principio de una revolución democrática” (107) basada en una nueva institución de lo social. El Mocase-Vía Campesina ${ }^{1}$ amalgama su propio marco de referencia a partir de la experiencia de lucha local con discursos externos y globales como el ecologismo y el conservacionismo, y recibe influencias de otras experiencias, como la del Movimiento Zapatista de México (EZLN) (De Dios 2009) o el Movimiento de los Trabajadores Rurales Sin Tierra (MST) de Brasil.

En este proceso, muchas mujeres se han convertido en militantes de base, encargadas de proyectos productivos e implementadoras de programas de derechos sexuales y reproductivos en sus comunidades. Muchas veces ellas fueron iniciadoras e impulsoras de formas de protesta como "pararse frente a las topadoras 2 ", y varios de sus compañeros destacan su participación como mujeres "valientes" y "luchadoras" que "empujaron a sus maridos".

Este artículo presenta reflexiones en torno a la participación femenina en este movimiento campesino, que se desprenden de una investigación más amplia de corte etnográfico (véase Guber 2011). El objetivo más específico es aproximarnos a relatos de vida de mujeres que son militantes históricas ${ }^{3}$ activas de la organización y explorar los sentidos que han construido sobre su trayectoria

1 Como se explicará más adelante, en el 2001 el movimiento se dividió en dos grupos: Mocase y Mocase-Vía Campesina. Este artículo se concentra en el último.

2 Se refiere a un tipo de máquina excavadora utilizada en la construcción o en la minería para corte y arrastre de tierra, que era empleada por empresarios para entrar de manera violenta a los terrenos donde se hallaban las viviendas y destruir los hogares de los campesinos.

3 Militante o compañero "histórico/a" es la expresión que utiliza la organización para hacer referencia a aquellos que forman parte del movimiento desde sus inicios, la mayoría de los cuales ocuparon un papel central durante su fundación, y aún hoy participan activamente. 
propia. Nos preguntamos por el impacto de la militancia en el movimiento respecto a la (re)configuración de los distintos espacios y roles en las relaciones de género y de familia.

Los ejes de la discusión parten de las narrativas de las mujeres entrevistadas y se orientan hacia la reconstrucción de sus motivaciones iniciales para participar, y a la valoración que realizan de las transformaciones ocurridas en sus biografías a partir de su desempeño político. Se sugiere la presencia de cambios sustanciales en la autopercepción de las posiciones y de los roles asignados a cada uno de los géneros, como producto de un proceso de creación de redes de solidaridad, emociones (Jaspers 2012) y lealtades afectivas que surgen de la experiencia colectiva. Consideramos que estas modificaciones no han sido incentivos para la participación política, puesto que las motivaciones iniciales se vinculan con lo que denominamos un anhelo por participar en la vida política, entretejido con la vivencia de ser campesinos explotados y con afectos hacia figuras de referencia.

Las preocupaciones de este trabajo se enmarcan en la línea de los estudios feministas. Este marco teórico, si bien cubre un gran abanico de perspectivas, se distingue por el enunciado común de que el género constituye una dimensión de la desigualdad social (Barbieri 1998), y no un área de estudios sobre "asuntos de mujeres” (Lamas 1999). De este modo, la categoría género es entendida aquí fundamentalmente en tanto forma primaria de relaciones significantes de poder (Scott 1990). En el mismo sentido, los análisis feministas han incorporado en las ciencias sociales la dimensión política de la vida cotidiana y han resituado la relevancia de la experiencia de las mujeres (Mies 1998) y de aquel ámbito considerado tradicionalmente como privado o doméstico (Segalén 1992), en donde el papel de las mujeres es, más que todo, de cuidadoras (Di Liscia 2007; Murillo 1996) y que puede extenderse al grupo o comunidad (Palacios 2011).

En este análisis se presentarán tres historias de mujeres obtenidas a partir de relatos de vida 4 (Wacheux 1996) producidos durante convivencias de algunos días en las viviendas campesinas de las entrevistadas. Ellas han sido elegidas de un conjunto total de diez narrativas testimoniales y entrevistas en profundidad (Atkinson 1998), con base en su representatividad (Pujadas 2000) y siguiendo el criterio de saturación de la información ${ }^{5}$ (Bertaux [1980] 1999). Los testimonios

\footnotetext{
4 De acuerdo con Wacheaux (1996), esta técnica consiste en una forma particular en la cual el investigador le propone al sujeto estudiado que cuente toda o una parte de su experiencia vivida, procurando limitar al máximo sus intervenciones.

$5 \quad$ Según este autor, "el corte significativo se da en el punto de saturación que por supuesto es necesario sobrepasarlo para asegurarse la validez de las conclusiones” (Bertaux 1999, 7).
} 
fueron obtenidos en el primer trimestre del 2016, durante una estancia de trabajo de campo con las familias de una de las comunidades de base $e^{6}$ de la organización. El argumento se desarrolla a partir de dichos relatos y parte de la noción de que las elecciones, puntos de vista y deseos de los sujetos particulares -en este caso, las mujeres militantes- son los microfundamentos de la acción colectiva (Jasper 2012), y permiten una posible reconstrucción de algunos puntos de vista culturales del movimiento social ${ }^{7}$ (Melucci 1996).

En Argentina son escasos los estudios que han abordado profundamente la problemática de la participación de mujeres rurales en movimientos sociales (Giarraca 2001). En este trabajo retomaremos investigaciones realizadas con el MST de Brasil, con quienes el Mocase-VC mantiene relaciones fluidas (Durand 2006), y con otros movimientos rurales de mujeres en los cuales sí se han abordado extensamente asuntos similares desde una perspectiva de género (Carneiro 1994; Da Silva 2004; Ferrante et al. 2013; Furlin 2013; Lechat 1993; Paulilo 2009; Paván 1998; Pinto 1992; Salvaro, Lago y Woolf 2014; Teixeira 1994).

El artículo se organiza en cuatro secciones. La primera cuenta con dos subsecciones que enmarcan el estudio en las líneas teóricas y discusiones en las que se inscribe. En primer lugar, se presentan los trabajos previos sobre el Mocase-VC y otros sobre género y política en movimientos campesinos similares. A continuación se aborda el estudio de las emociones en los movimientos sociales. Las siguientes tres secciones se estructuran a partir de una historia de vida cada una, las cuales van desplegando los distintos puntos del argumento que desarrollamos.

6 El Mocase-VC está constituido actualmente por diez centrales campesinas, distribuidas en distintas localidades de la provincia de Santiago del Estero, Argentina. Cada una de ellas reúne, a su vez, un número variable de comunidades de base, que se conforman como el nivel más básico de organización de las familias campesinas. sistema de significados que los actores ponen en juego de manera dinámica y activa, y más específicamente el concepto de red (network o web), el cual permite centrar la atención en los modos en que los lazos interpersonales sostienen al movimiento social, infundiendo nuevos sentidos culturales y prácticas políticas en relación con asuntos centrales como la naturaleza, la identidad o las relaciones vecinales. 


\section{Organización política y relaciones de género en el Mocase-VC}

Como mencionamos, la gesta del Movimiento Campesino de Santiago del Estero (Mocase) se inicia formalmente en los años noventa a raíz de conflictos por la tenencia y propiedad de las tierras (Michi 2010). En Santiago del Estero, uno de los principales problemas del sector campesino es la inseguridad jurídica sobre la tierra que ocupa. La situación más extendida es la posesión de tierras privadas o fiscales, donde no se ha podido acceder a las escrituras de dominio (De Dios 2009). No obstante, de acuerdo con lo que se conoce como "ley veinteñal", la legislación argentina reconoce el derecho de los pobladores a la propiedad de la tierra cuando han ejercido una posesión pacífica y continua por más de veinte años, o allí donde han actuado "con ánimo de dueño", sin reconocer a otro propietario distinto de ellos mismos ${ }^{8}$.

Tradicionalmente, las tierras que ocupaban muchas familias campesinas de la región eran consideradas improductivas y los pobladores sobrevivían allí mediante la producción para el autoconsumo, combinada con trabajos asalariados en condiciones de precariedad laboral. Sin embargo, durante las décadas del setenta y el ochenta se inició un proceso de "modernización" encarado por empresarios de origen extraprovincial, que al contar con la posibilidad de incorporar tecnología a la producción agropecuaria para la exportación se interesaron comercialmente en dichos terrenos. Una de las consecuencias directas fue la proliferación de acciones de desalojo y expulsión de los antiguos ocupantes de estas tierras - ahora valorizadas-, conocidas como "desalojos silenciosos” (Barbetta 2009; Dargoltz 1997; De Dios 2009; Michi 2010).

Las expropiaciones se profundizaron en la década del noventa, cuando la expansión de las producciones agroexportables mecanizadas (en especial, la soja transgénica) dio lugar a un cambio profundo en la estructura agraria. Estas dicas llevadas a cabo por el Mocase-VC en este terreno, véase Barbetta (2009).

9 De Dios (2009) ha explicado en extenso este proceso: "el modo típico de proceder podría sintetizarse así: las empresas o particulares compraban las tierras, por lo general, a familias tradicionales residentes en la Ciudad Capital de Santiago del Estero, que no las explotaban, y a sabiendas de que estaban ocupadas por un número variable de campesinos poseedores. Con las escrituras en su mano, calificaban de usurpadores a los pobladores y les iniciaban acciones legales para desalojarlos. Como consecuencia, ya sea por la falta de respuesta ante los requerimientos judiciales y la caída de los plazos procesales, o por la carencia absoluta de una defensa jurídica, los pobladores se veían sorprendidos de un día para el otro y expulsados de sus tierras 'legalmente', es decir con una sentencia de desalojo en su contra" (3). 
transformaciones ocurrieron en detrimento de los bosques, montes y suelos naturales y generaron desempleo, aumento de la pobreza, incremento de las migraciones y una precarización general de la vida rural (Díaz 2005). Asimismo, esta coyuntura de tensión jurídica y económica entre campesinos y empresarios sucedió en un marco social y político de dominación caudillista y autocrático, denominado “obraje político” (De Dios 2009), que se ha afianzado durante décadas mediante la hegemonía del gobernador provincial Carlos Arturo Juárez ${ }^{10}$. De acuerdo con los análisis de De Dios (2009) y de Barbetta (2009), la mayoría de los campesinos, además de ignorar sus derechos sobre las tierras debido a la falta de información, aceptaban como natural una posición subordinada o se sentían en inferioridad de condiciones para enfrentar a los sectores poderosos y carecían de los medios económicos para hacer escriturar sus propiedades. De este modo, los procesos expropiadores se fundaron en desigualdades extremas de poder y en el desconocimiento de los poseedores de los derechos que los asistían. Gran parte de los sentidos de oposición, a partir de los cuales se construye un movimiento campesino que se propone generar vínculos y redes de sociabilidad horizontales y solidarias entre el colectivo de campesinos, nacen de la reivindicación de sus derechos sobre la tierra, pero esencialmente de la confrontación con los sectores en el poder (Michi 2010).

Lo que nos interesa destacar aquí es el trayecto de esta organización, que emergió como una forma de lucha gremial y defensa jurídica, y evolucionó hacia la creación de una identidad colectiva en torno a la categoría de campesinos (Michi 2010). En el 2001, a partir de la fractura ocurrida por diferencias con respecto a la forma organizativa, las estrategias, los recursos y los grupos de apoyo (Durand 2006), continuaron dos grupos con los nombres de Mocase y Mocase-Vía Campesina. Este último asume una estructura horizontal y un accionar en alianzas con otros sectores nacionales (especialmente, los movimientos de desocupados) y globales, con otras organizaciones como la Coordinadora Latinoamericana de Organizaciones del Campo (CLOC) y la Vía Campesina.

En este proceso, los campesinos se consideran parte de un modo de vida que se opone al modelo dominante, que recupera y reelabora conocimientos

10 Juárez, del Partido Justicialista, gobernó la provincia en cinco oportunidades, entre los años 1949 y el 2003. Su mandato fue interrumpido primero por el golpe de Estado de 1976 y en el 2004, luego de denuncias de autoritarismo, escándalos de corrupción y prácticas ilegales; fue finalmente destituido por intervención del Gobierno nacional de Néstor Kirchner. Tras la intervención federal de la provincia, el informe del Ministerio de Justicia, Seguridad y Derechos Humanos para Santiago del Estero (2004) destacó, entre otros asuntos clave, la ausencia de separación entre el Poder Judicial y la gobernación de la provincia, la existencia de un aparato de inteligencia interna y la vinculación no transparente entre el poder económico y político de la región (Barbetta 2009). 
tradicionales y que propone transformaciones en varios planos. Por un lado, desde la construcción política, la participación directa a partir de procesos legales y legítimos y de respeto por los derechos humanos, y la noción de autonomía frente al Estado. Por el otro, desde la producción, el respeto por el medio ambiente, la conciencia ecológica y la economía con criterios que se distancian de la lógica de acumulación de bienes en favor de la noción de soberanía alimentaria. También emplean el concepto de territorialidad como el lugar donde se entretejen vínculos sociales solidarios, alternativos y justos. En el campo educativo, recuperan la trayectoria de la educación popular, con el fin de promover la autonomía y la participación horizontal en la producción de conocimientos y la formación política (Michi 2010). Debido a sus propuestas transformadoras, el Mocase-VC ha sido objeto de numerosos estudios que han analizado las condiciones socioeconómicas de su surgimiento, así como su recorrido político y el proceso de creación de una identidad campesina producto de las acciones colectivas (Dargoltz 1997; De Dios 2009; Durand 2006), o sus prácticas educativas (Michi 2010). Con base en estas lecturas, nuestro enfoque teórico y la experiencia en campo, cabe preguntarse en qué medida la participación femenina, en un movimiento que propone tales sentidos emergentes, modifica prácticas sociales basadas en el género y en el modo en que las mujeres se perciben a sí mismas.

Otros trabajos ya han señalado que la militancia femenina en movimientos sociales - no necesariamente feministas - contribuye a transformar concepciones previas de lo femenino, así como las relaciones familiares. Rubin (1998), por ejemplo, en su estudio sobre movimientos populares urbanos en Ciudad de México, resalta que ciertos ámbitos supuestamente “apolíticos”, tales como la vivienda, el mercado o las calles, pueden convertirse en importantes espacios de discusión política, de conocimiento, de fortalecimiento de lazos comunitarios y de resignificación de cuestiones ligadas a la clase y el género. Este autor ha señalado que, para el caso de las mujeres militantes, su participación en dichos movimientos ha implicado el desafío de enfrentarse a las nociones dicotómicas previas de lo que cuenta como vida doméstica y vida pública.

En contextos rurales, trabajos como el de Ferrante et al. (2013), Lechat (1993), Pinto (1992) o Teixeira (1994) se han ocupado de analizar las potencialidades y limitaciones de la integración de mujeres en diferentes movimientos sociales. Todos ellos apoyan la idea de que la presencia femenina en sí, su inclusión en la vida política al lado de los hombres y el hecho de construir nuevas redes de sociabilidad fuera del entorno familiar y doméstico elevan el prestigio social de las mujeres, reducen la situación de exclusión y generan una redistribución en las relaciones de poder. Por otra parte, Paulilo (2009), en un estudio 
comparativo de reivindicaciones exclusivamente femeninas entre militantes del MST y del Movimiento de Mujeres Campesinas (MMC) de Brasil, discute los alcances del espacio público y masculino como lugar privilegiado de la participación política, de cara a los intereses feministas. La autora sostiene que para las militantes del MST, influidas por el marxismo, la concepción de género se subordina a la de clase y conciben a la mujer rural como un ejemplo específico del fenómeno general de las clases sociales, como lo ha explicitado Scott (2001). En el MST, del cual el Mocase-VC recibe fuertes influencias y con el que mantiene un contacto asiduo mediante visitas, encuentros e intercambios periódicos entre militantes de ambas organizaciones, las reivindicaciones colectivas se basan en una imagen de la familia como un todo cohesionado, que oculta el papel subordinado que tradicionalmente tiene la mujer en la organización familiar. La militancia se propone como un terreno mixto en el cual hombres y mujeres "son iguales” y las transformaciones en las relaciones de género se asumen como producto del cambio social a realizar junto a los compañeros y de la construcción de un "nuevo sujeto" mediante la lucha colectiva (Paulilo 2009). Sin embargo, este y otros trabajos (Da Silva 2004; Furlin 2013; Paván 1998) resaltan las contradicciones entre las propuestas y las posibilidades de concretarlas en la convivencia diaria de los campamentos o asentamientos de la organización, donde persisten muchas desigualdades de género.

Durante el trabajo de campo y la realización de entrevistas en profundidad a hombres y mujeres militantes, he podido observar similitudes entre el contexto brasilero y el estudiado en Argentina en la propuesta con respecto a las relaciones de género. También allí se asume el ideal de la familia como un todo unificado con intereses comunes, y se cree que los cambios en las relaciones de género son parte de un "proceso" y de un "aprendizaje” que van construyendo de modo colectivo. En esta creación de un modo de vida con valores y prácticas que se oponen al individualismo capitalista, prevalecen los sentidos de unión ("solo unidos podemos hacer algo"), de solidaridad y de "pensar en el vecino", que a su vez representan el orgullo y la dignidad del camino recorrido. En relación con el género, la búsqueda se orienta hacia la simetría de roles y hacia la igualdad, tanto en la esfera política como en el interior de las relaciones familiares: "acá todos hacen todo". También se acepta que la organización —mediante algunos de sus integrantes o en las reuniones asamblearias- se inmiscuya en asuntos familiares cuando se lo considere necesario, porque "lo que se busca es mejorar la vida de todos”. No existen espacios exclusivos para las mujeres, ya que se considera que hombres y mujeres deben "cambiar" en conjunto y que los problemas e intereses les conciernen a todos por igual. 
No obstante, aquí proponemos una aproximación alternativa al problema, partiendo de las historias de vida de las mujeres militantes, lo que nos permite esbozar la presencia de actuaciones colectivas que han facilitado transformaciones favorables de los intereses de las mujeres, y la emergencia de solidaridades que han creado caminos diferentes en relación con el género. Creemos que los puntos de vista de las mujeres sobre sus motivaciones iniciales y los cambios producidos a partir de entonces son cuestiones imbricadas que permiten reconstruir trayectorias de fortalecimiento y de creación de nuevas identidades por las que podemos indagar desde una perspectiva generizada (Acker 1990).

\section{Emociones, experiencia colectiva y nuevas subjetividades}

Con los relatos de vida que presentamos en el siguiente acápite buscamos desarrollar el argumento de que la participación política en el Mocase-VC ha reorganizado, entre las mujeres militantes históricas, los valores que sustentan las relaciones de género. Esta observación se apoya en las modificaciones sustanciales ocurridas en sus trayectorias de vida, lo cual se advierte en varios planos: la planificación familiar, la distribución de tareas en la vida doméstica, las decisiones en aspectos vitales de las relaciones de pareja, los usos del tiempo y la nueva identidad como sujetos políticos, entre otras cuestiones que aparecen en las historias. Hallamos que estas transformaciones - que en los relatos suelen expresarse como un renacer o una segunda vida- no han sido perseguidas intencionalmente ni han sido un motor para la participación política, sino que son producto de un proceso de creación de solidaridades y de experiencias emocionales compartidas.

La visión que asumimos se enriquece con los estudios de las emociones en los movimientos sociales, que han planteado que los grupos tienden a fortalecerse cuando comparten emociones en respuesta a ciertos eventos que refuerzan las lealtades afectivas y la identidad colectiva. La energía emocional generada en situaciones cara a cara provee a los agentes sociales de conciencia grupal y contribuye a la motivación para sentirse parte de empresas colectivas (Jasper 2012). De acuerdo con el mismo autor, las lealtades y la identidad colectiva "amplían la lista de metas de un individuo al incluir beneficios para el grupo, más allá de los que recibe ese individuo como miembro. Esas metas no son del todo egoístas, ni tampoco plenamente altruistas” (52). Es relevante señalar que en los recorridos personales que analizamos se observa de manera recurrente la profundización del compromiso con la identidad colectiva, la cual gradualmente va ocupando un 
espacio más amplio en la vida cotidiana de las mujeres militantes y genera una reorganización de la vida social y las subjetividades, de modo que el plano individual y el colectivo aparecen como un todo entrelazado.

Por otro lado, subrayamos otro punto central que emerge de los relatos individuales y la atención a las trayectorias subjetivas de las mujeres militantes, y que se vincula con el anhelo por la vida política y el afecto hacia figuras de referencia, como estímulos que las impulsan a la participación. Esto agrega una nueva dimensión al análisis de las motivaciones colectivas, cuyo estudio deberá ser profundizado en otro trabajo. Desde la perspectiva de las emociones, dicha idea hace eco de otros estudios que han encontrado que "muchos de los movimientos que parecen interesados instrumentalmente por el poder o sus beneficios materiales, están de igual forma motivados por la preocupación respecto a la dignidad humana que suponen los derechos políticos” (Jasper 2012, 51).

\section{La apropiación de las reivindicaciones colectivas}

\section{Matilde $^{11}$}

La infancia de Matilde se desarrolló en un paraje perteneciente al actual territorio del Mocase-VC, donde fue criada por sus abuelos y junto a sus tíos. Luego del parto, su madre había sido enviada por la familia a trabajar como empleada doméstica a la ciudad capital a los diecisiete años, a causa de la vergüenza que les representaba un embarazo sin una relación de pareja estable. Su abuelo era un peón rural de hacienda; durante un tiempo percibió un salario informal y luego solamente trabajó a cambio de poder permanecer en una pequeña parte de ese terreno como productor para el autoabastecimiento. De acuerdo con las memorias de Matilde, si bien las actividades relacionadas con la siembra y la cría de animales ocupaban a la familia por completo, las tareas domésticas eran solo de las mujeres. La siembra se realizaba mediante el arado artesanal y la construcción de cercos - tareas consideradas masculinas-, y el cultivo propiamente, en el cual trabajaban hombres y mujeres. En la cría de animales como cabras y chivas también participaban los niños y jóvenes. Por otra parte, en condiciones

11 Los nombres propios y otros datos personales han sido omitidos o modificados con el objetivo de preservar el anonimato de las entrevistadas. 
signadas por la falta de servicios básicos y la precariedad material, una de las tareas “femeninas” que demandaba mucho tiempo consistía en el acarreo de agua desde el aljibe de los dueños de la propiedad hacia depósitos en su rancho familiar, ubicado a una distancia considerable a pie.

Estas memorias guardan similitud con otros estudios sobre la agricultura familiar en contextos latinoamericanos, en donde se ha observado que se impone una división sexual del trabajo orientada por roles de género tradicionales, y a las mujeres se les asignan aquellas tareas consideradas domésticas y a los hombres, los trabajos agrícolas y pecuarios considerados como tareas productivas o, más estrictamente, como "producción”.

Las actividades domésticas femeninas suelen incluir la limpieza de la casa, la crianza de los hijos y la preparación de los alimentos, entre otras; y prevalece la concepción de que el trabajo de las mujeres en las actividades productivas tales como la cosecha se tratan de una "ayuda”, lo que invisibiliza las tareas femeninas (Brumer 2004; Carneiro 1994; Salvaro, Lago y Wolff 2014; Woortmann 1990). En este sentido, Matilde identifica como tareas de la casa aquellas asignadas exclusivamente a las mujeres:

Y [tareas] de mujeres... cocinar, lavar, regar la huerta... el tema de los animales... mi abuela por ejemplo iba a ordeñar la vaca, y ella hacía los quesos, los dulces, y nosotros [los niños] nos encargábamos de las gallinas; de cuidar las chivas, que ahora es muy común que se ocupen las mujeres, nosotros muy rara vez, salvo que no esté mi abuelo, sino él se encargaba del tema de los animales.

Su primer contacto con la ONG que luego daría lugar al Movimiento Campesino ocurrió a la edad de dieciséis años, en 1991. En su relato aparece imbricado con lazos de afecto - especialmente hacia su abuelo, a quien llama "padre"- y a cuestiones que enlazan su propia biografía con la trayectoria de la población campesina local, oprimida por la complicidad del poder económico, político y judicial de la provincia. Esta identidad contribuye a crear y a enmarcar un deseo personal - transmitido por su abuelo-, de revertir una situación de múltiples injusticias vividas históricamente. De esta y de las siguientes historias de vida se desprende que la referida cuestión de la tierra, clave en la conformación del movimiento desde otro nivel de análisis (Durand 2006), no explica en este o en muchos otros casos los alicientes individuales para la participación en la organización. El siguiente fragmento de entrevista nos permite esbozar la presencia de razones y afectos entrelazados que complejizan los sentidos que ha tenido la organización campesina en esta biografía particular, lo cual, como veremos luego, contribuye a reconstruir las significaciones colectivas: 
A: ¿Y qué fue lo que la llevó a usted a interesarse en participar de esa organización?

M: Y... a mí porque mi abuelo me contaba mucho de lo que pasaba antes de vivir ahí... Él había quedado huérfano a los trece años y desde los trece años que empezó a trabajar de peón rural por distintas estancias, entonces él me contaba, así de noche, nos sentábamos junto al fuego y me contaba sobre lo mal que los trataban en el campo, que a él no le ha tocado personalmente pero sí a compañeros que los estaqueaban ${ }^{12}$ al sol. Él lo ha vivido eso... así como cuenta la historia... que los patrones cuando estaban muy cansados o no cumplían el horario de trabajo los estaqueaban al sol, los ataban de pies y manos y encima les echaban agua [...] Entonces él contaba que antes a los peones los trataban muy mal, existía mucho el caudillismo y no los dejaban que salgan a votar... entonces ellos a veces se juntaban. Él era como muy rebelde y decía que no tenía quien lo acompañe por el miedo, y cómo los maltrataban. Por ahí su rebelión, los compañeros no lo acompañaban [...] Y cuando llega $\mathrm{A}^{13}$ él conocía todas las problemáticas de las tierras, los desalojos y todo eso... como que mi abuelo tenía la idea de hacer algo pero no sabía cómo. [...] Entonces yo le decía a mi abuelo: "si van a armar algo [se refiere a organizarse políticamente], yo me voy a ir a trabajar ahí” y él me decía: "bueno, por lo menos si yo no he podido que alguien siga con lo que he pensado, de hacer un poco más de justicia”, decía él. Y él [A] decía de dar a conocer a la gente sus derechos, sobre todo, que la gente no sabía. Y así empezamos.

Retomando a Jasper (2012), este estudio se inscribe en la discusión en torno a los motivos para la acción colectiva que sostienen que:

El deseo de producir un efecto sobre el mundo es otra gran familia de motivaciones, junto con las emociones que conlleva. En los movimientos sociales, este deseo proviene a menudo de una perspectiva moral - o una ideología- que sugiere que el mundo debería ser diferente a como es. (52)

El relato de Matilde ilustra la disposición y el deseo de intervenir activamente en la vida política — que se ha hallado de manera manifiesta y recurrente en las mujeres militantes "históricas"-, aun antes de que estas intenciones puedan aflorar. De este modo, para los casos de mujeres militantes históricas del movimiento, con un nivel de compromiso más acentuado que el de otros de sus

12 Se refiere a la antigua práctica denigrante de atar a los peones rurales a palos clavados en la tierra, a modo de represalia. inicios de la organización, como ha sido detallado en otros trabajos (Durand 2006). 
compañeros, argumentamos la presencia de un anhelo por la vida política que emerge como oportunidad de expresarse a partir de dicha coyuntura y que no puede reducirse directamente a un interés material:

A: ¿Y ustedes tenían miedo de que los desalojaran también?

M: No, nosotros no, porque vivíamos ahí en el campo y mi abuelo nunca ha querido ningún pedazo de tierra, pese a que por ley le correspondía, así que él, cuando se ha jubilado, él con sus aportes le iba aportando a mi abuela, como autónomos, así que ella también se ha jubilado. Y después, cuando yo me casé, ellos solitos se han venido a vivir aquí a Quimilí y han dejado allá donde vivíamos.

A: ¿Y en ese momento pensaba que la organización podía ayudarla en algo?

M: En realidad la ayuda no era para mí, porque ninguna de esas problemáticas las había vivido yo, era para los demás, para poder ayudar a los demás.

A: ¿Y le gustó?

M: Sí, a pesar de haber tenido quince... no, dieciséis años, a pesar de ser muy adolescente, inmadura sería... porque yo salía de una realidad de allá del monte aquí al pueblo por ejemplo, y después los diferentes parajes... Y así hemos empezado y he salido mucho... y aquí era que por tradición, bueno, ahora ha cambiado mucho, pero antes aquí era que la mujer se tenía que casar y ocuparse de la casa y los hijos, y nada más. El marido se tenía que ocupar de mantener, no se participaba en ninguna cosa.

Sin embargo, a raíz de su participación en la organización, Matilde no solamente construye nuevos espacios de socialización y “ayuda a los demás”, sino que sus actividades cotidianas y su papel dentro de la familia comienzan a ser modificados a partir de las nuevas responsabilidades y redes de sociabilidad. Este nuevo papel político implica viajes periódicos a la ciudad más cercana, asistencia a reuniones y recorridos por diferentes parajes como tarea fundamental del trabajo de base que realizaban en un comienzo los participantes de la organización. A partir de estas nuevas circunstancias, tiene la posibilidad de cursar estudios secundarios y permanece de lunes a viernes en la casa donde la alojaban compañeros de la organización. Transcurridos unos años comienza a encargarse de la administración del Mocase-VC. En esa época conoce a su actual pareja y padre de sus dos hijos, con quien comienza una vida familiar que reconoce como diferente a la que hubiera tenido en el monte. Con ello se refiere particularmente a sus conocimientos sobre salud sexual y reproductiva, especialmente la anticoncepción y la planificación familiar, y la reasignación de papeles más simétricos entre ella y su pareja. Esto lo atribuye a la “formación” diferente que adquiere 
durante su participación en el movimiento, en cuyas asambleas y reuniones se discutía la necesidad de hacer más simétricos los roles de género, y al hecho de que, gracias a la colaboración de sus compañeros, pudo realizar estudios secundarios en la ciudad principal de la localidad:

A: ¿Y qué fue lo más importante que le aportó a usted el movimiento?

M: La formación. Y yo siempre digo, el movimiento es como mi casa, que yo aprendo a integrar mi familia en una gran familia.

A: ¿Y le trajo conflictos con su compañero?

M: Al principio sí, los primeros años es difícil... por el tiempo, por los hijos, pero él también viene de esa cultura en la que la mujer es de la casa. Pero él me ha conocido ya participando en la organización, pendiente de ir a reuniones y todo... Un día hablamos y le dije: "vos ya me has conocido así y es lo que yo quiero y me tendrás que ayudar con los hijos y te tendrás que acomodar”, “¿cómo que yo voy a cambiar al niño si se orina?”, me decía él [ríe]. Yo a veces pienso, por eso... quizás hubiera terminado con nueve, diez hijos, o andá a saber cuál hubiera sido mi destino, por empezar estudiar, no hubiera estudiado, porque al colegio no me habían mandado, y menos hubiera tenido un trabajo así.

Actualmente, Matilde vive con su marido y sus dos hijos en una vivienda sencilla ubicada cerca de una de las centrales del Mocase-VC. Durante la jornada completa participa en la administración de la organización y también colabora con otras áreas ${ }^{14}$, como las de formación y de salud. En dichas áreas identifica como problemáticas actuales de género la enseñanza de salud sexual y reproductiva (impartida a los jóvenes en la Escuela de Agroecología) y casos recientes de violencia de género que han empezado a emerger tímidamente en las comunidades de base. También hace mención de los problemas de salud que afectan a embarazadas debido a la polución y el veneno de las fumigaciones en campos aledaños, una cuestión que en otros contextos ha sido abordada pero que suele permanecer oculta debido a la invisibilidad del trabajo femenino en la producción (Paulilo 2004).

14 Las acciones del movimiento se organizan en siete áreas: territorio, tierra, formación, salud, comunicación, proyectos y producción. Durante las asambleas y de forma rotatoria (aproximadamente cada tres meses), se decide quiénes participarán en cada una de ellas con el fin de que todos los integrantes tengan la formación y competencia necesarias para desempeñar cualquier función. Este modo de organización por tareas es indistinta según el género: todas las mujeres y hombres de la organización deben pasar por todas en diferentes momentos, puesto que la asignación asamblearia implica un compromiso obligatorio. 


\section{Horadar las fronteras del ámbito doméstico}

\section{Lidia}

Si bien Lidia es originaria de un paraje cercano a la localidad santiagueña de Quimilí, en su historia de vida también aparecen la necesidad de migrar y el empleo doméstico informal cama adentro en la ciudad, y en condiciones que ahora puede reconocer como de explotación. Se trata de un destino común aunque poco deseable que entre 1970 y 1990 era una de las pocas alternativas de empleo para las mujeres jóvenes de las zonas rurales santiagueñas. Las condiciones de semiesclavitud y de violencia -incluyendo manifestaciones físicas- por parte de los patrones no eran menos duras que aquellas que sufrían los hombres rurales empleados: "no me dejaban salir... bueno, la pasé de todo un poco, me pegaban...”.

En el caso de Lidia, que además tuvo que dejar a un hijo suyo al cuidado de los abuelos en su paraje, al maltrato laboral se agregan situaciones de violencia por parte de una pareja con quien convivía en la ciudad (ya trabajando como empleada informal "por hora"). Frente al recrudecimiento de las agresiones físicas, reunió algo de dinero y en 1995 decidió regresar a su lugar de origen, donde conoció a una nueva pareja. Recuerda que eran épocas en las que los hombres eran empleados temporalmente en obrajes y otras changas, y el resto del tiempo —que aún a veces alternan- las familias subsistían con la producción para el autoconsumo. Sin embargo, las "épocas del obraje" implicaban mucho sacrificio porque las familias enteras debían trasladarse al lugar de trabajo y abandonar sus ranchos, la siembra y los pocos animales que poseían (Durand 2006). Cuando había dinero de por medio, lo administraba el hombre, quien estaba autorizado a tomar las decisiones con respecto a la economía y la organización de la familia. Las mujeres se ocupaban de las tareas domésticas y de crianza pero también "ayudaban" a sus maridos en las tareas del obraje:

A: ¿Y ahí cómo era un día?, por ejemplo, ¿qué hacía cada uno en esa época del obraje?

L: Él era encargado de varia gente que cortaban leña, hacían carbón. Y yo lo único que hacía, que no tenía más nada que hacer porque lo único que tenía era un encatrado ahí para dormir, un poquito de olla y nada más y limpiar ahí ese pedacito y nada más [...] Después a la noche cuando se hacía carbón lo acompañaba, iba a las parvas. Andaba con él en las parvas donde se hacía carbón y eso así hasta que pasó la época esa. 
En aquella época, Lidia conoció el movimiento, ya con el nombre de Mocase-VC, que había conseguido ser beneficiario de un subsidio de la Embajada holandesa para la producción caprina, destinado a las familias pertenecientes a la organización, y administrado cooperativamente como “crédito rotatorio” (véase Durand 2006). Para ese entonces, la organización había identificado la falta de participación femenina como un problema interno y había comenzado a organizar "talleres de formación” para hombres y mujeres, en los cuales se discutía la importancia de la participación de “toda la familia en su conjunto”. En palabras de la entrevistada: “...porque veían que aquí las mujeres no podíamos nosotros decidir nada si no estaba el marido. No podíamos decir nada porque el marido era el jefe. ¿Entonces, cómo iban a entrar a hablar, cómo entraban?”. A raíz de estas preocupaciones, se les exigió a todas las familias que las mujeres participaran en dichos talleres, como contraprestación obligatoria para recibir el fondo caprino. Así, la participación femenina, limitada por la interdicción de sus parejas, pasó a ser un asunto que le incumbía a todo el colectivo, y en el cual se consideraba que podían y debían inmiscuirse el resto de los campesinos organizados:

L: A veces yo tenía que salir por ahí y entre todos decían "bueno, que vaya”. Tenían la confianza de que yo pueda representarlos en otro lugar. Y él no quería que yo salga. Entonces entre todos era de ponerle en claro por qué, qué es lo que hay que no pueda salir, si todos los compañeros están diciendo que sí puede, qué es lo que hay. Bueno, así era.

De esta manera, la trayectoria le aporta un nuevo contexto etnográfico al debate en torno a las limitaciones de la participación femenina en movimientos sociales por la interdicción de sus parejas masculinas (Acosta y Bonfiglio 2014), y muestra que no en todos los casos la organización opera como una extensión de los roles tradicionales de género. En esta situación, a partir de desencadenantes como el fondo caprino y los talleres, comenzaron a cuestionarse los roles de género y la división de tareas dentro de cada familia - antes muy de acuerdo con el modelo tradicional-, y las mujeres empezaron a sentirse legitimadas por la voz del colectivo organizado. A diferencia del MST, en el cual el debate en torno al género se ha introducido por presiones externas y por la influencia de organizaciones de financiamiento internacional (Furlin 2013), en el Mocase-VC comenzó a partir del reconocimiento de problemáticas internas en las etapas tempranas de la organización.

Por otro lado, desde la perspectiva de Lidia y desde los significados que ha construido sobre su participación política, la cuestión de la tierra y los desalojos tampoco son el motivo central de ingreso al Mocase-VC. Nuevamente, las motivaciones iniciales para organizarse entremezclan el deseo de participar en la 
vida política con un fuerte sentimiento de haber sufrido injusticias individuales y extendidas a un colectivo que comienza a identificarse como campesino:

A: ¿Y usted se acuerda, cuando le dijeron de participar, si le entusiasmó, o si fue... al principio digo, no... por las cabras?

L: No, ¿sabe qué?, a mí siempre me ha gustado así lo social, participar en charlas, yo quería participar por ejemplo en las iglesias, pero a mí nunca me dejaban, porque yo siempre he trabajado [...]

A: Le gustaba por ejemplo conversar. O sea que de entrada [desde un principio] le gustó.

L: La primera vez que entré ahí estaba como sapo de otra represa, no entendía nada; y después me fui adaptando y ya conociéndolo [...] Porque a los pocos tiempos empezamos a organizar la primera... empezaron a tener problemas los compañeros por los problemas de territorio, de campo. Había compañeros presos [...] Los ponían presos y pasaban tanta injusticia; y todos conversábamos el porqué, el cómo, talleres, formación y después, a través de esto, qué hay que hacer... mucha injusticia, como que no nos lleva el apunte la justicia, entonces hay que organizar una marcha. Una marcha bien organizada y empezar a discutir cómo vamos a hacer si no tenemos dinero. [...] Y cuál va a ser la mirada de la marcha, a dónde se va a hacer, con quiénes, cómo, con qué organización. A veces nos quedábamos hasta las doce, una de la mañana; así medio dormidas [...] ¡Ah, eso me encantaba! A mí me encantaba pelear [ríe]. La injusticia me ponía mala. [Énfasis añadidos]

A partir de estas historias de vida es posible reconstruir la existencia de eventos clave en el trayecto del movimiento, que por su impacto emocional han ido forjando la identidad del Mocase-VC y han fortalecido el compromiso y las lealtades internas. Este es un tema que se ha desarrollado y discutido en extenso en la organización (Barbetta 2009; De Dios 2009; Michi 2010), pero no desde una mirada que tenga en cuenta la condición de género de sus integrantes, la cual permite dimensionar la trascendencia de este nuevo espacio para las mujeres cuyos destinos percibían limitados al ámbito del hogar y al sometimiento a la autoridad masculina.

Un ejemplo de eventos significativos son lo que denominan retomas y el aguante, que consisten en acciones colectivas que se realizan cuando toman conocimiento del desalojo de alguna familia de la organización. El modo de operar es comunicar a todas las centrales y comunidades de base, desde donde llegan hombres, mujeres y niños a reubicar a las familias desalojadas en sus antiguos ranchos (y reconstruirlos, si han sido quemados o destruidos), y luego hacer un acampe que puede durar varios días o semanas. Mientras se realiza la custodia 
se convive de modo comunitario (con grupos mixtos y tareas rotatorias) y se discute en asamblea el plan a seguir:

El aguante es una ayuda material y espiritual al mismo tiempo, donde se expone el propio cuerpo - expuesto a la violencia policial y a las topadoras - y el espíritu de lucha para sostener a aquellos que pueden perderlo todo en una sola noche. Es una actividad de apoyo a otras familias en la cual la mística de la acción de resistencia se une a la idea de peregrinación, de movimiento hacia otro espacio [...] (Heller 1998, citado en Durand 2006, 140)

En el caso de Lidia, estas vivencias y su nuevo rol activo en la organización le han aportado sentimientos de satisfacción y de dignidad, y a su vez la han acompañado en la transformación de su vida familiar, pues ha creado nuevos lazos de afecto que ella considera ahora como su familia, por lo cual rememora esos tiempos como de "doble lucha”:

L: Bueno, eso, y creo yo que a muchos compañeros y compañeras ha sido el punto fuerte cuando hemos hecho la retoma en el Lote $6^{15}$. Te decía yo, en particular mío, que yo tenía doble lucha. Porque justo tenía problema con mi pareja.

A: ¿Ahí no estaba su marido?

L: Sí, estaba, pero tenía problemas, él no quería que vaya. Y a mí esas cosas me gustan. Cuando decían quién va ir al frente, yo era la primera. [...] No me siento obligada a estar ahí porque soy del movimiento y hay instancias en que no debemos faltar. [Es una] obligación de corazón. [...] Y le decía a mi madre: "Mire, si me llegan a matar, póngase contenta porque estaba haciendo algo que a mí me gusta, y voy a ir con mucha alegría si me llegan a matar. Porque eso me gusta”.

A: Una experiencia de vida.

L: Hermosa, porque llegar ahí a ese lugar, yo no lo conocía. Ver toda la casa en polvo, era abrazarse, llorar y llorar porque se te mezcla la alegría de poder sacar a alguien [...] Después que terminamos de sacar metíamos las cosas para adentro, lo que estaba afuera que ellos le han sacado. Lo que no era nuestro, afuera, lo que es nuestro, adentro. Y ahí llegar y abrazarte y llorar porque era una mezcla de alegría de estar...

También se desprende de este relato la presencia de alteraciones importantes en la subjetividad y en la denominada vida personal o íntima, las cuales no parecen haber sido alicientes originales para iniciarse en la participación política, o cambios intencionalmente buscados. Lidia, por ejemplo, describe que 
luego de la experiencia en Lote 6 sintió la fortaleza para dejar de aceptar las presiones de su pareja. Sin embargo, transcurrieron unos años más durante los que intentó continuar con su participación política y también con su marido, lo cual agudizaba los conflictos, hasta que decidió separarse y recurrir a la ayuda de la organización, que ha resultado fundamental para rearmar su vida:

A: ¿Y a partir de eso cómo hizo para arreglarse? ¿Dónde vivió, de qué trabajaba?

L: Yo siempre he querido el campo, mi familia no me aceptaba. Y cuando yo avisé aquí en la organización, los compañeros todos han estado dispuestos, Rincón de Saladillo, Santa Rosa, Lote 5, Pampa Pozo [nombres de las diferentes comunidades de base]. En todos los lugares me ofertaron para que me vaya quedar.

A: ¿Y quién la ayudó?

L: Los compañeros. Entonces un buen día dije: "no doy más, no voy más". Vine y lo presenté en la central, era un día lunes y dijeron, "bueno, para mañana vamos. Pero usted levante lo que le dan, no pelee nada”, porque yo estaba muy delicada [se refiere a problemas de salud]. Me vengo a donde he venido, tenía que poner mis chivas en un corral del vecino. ¿A dónde iba a hacer rancho? No tenía nada, así que los compañeros ahí me han ayudado a hacer rancho. La primera noche ha llovido. Y ellos me han acompañado por lo menos quince días con todo eso, con los animales, con todo. Y así después iba, venía, y hasta hoy. Hoy hace como trece, catorce años que vivo siempre en esa casa. La casa es de todos.

Estos hechos nos acercan a comprender la valoración actual de Lidia de los aportes de su participación política en el movimiento campesino y el alcance del vuelco que ha implicado en su biografía - o, en sus propias palabras, de su renacer-, de un modo total e integrado. El relato agrega un testimonio de las redes de solidaridad y las lealtades afectivas por fuera del ámbito doméstico tejidas a partir de la experiencia colectiva — con su potencial transformador de las relaciones de género-.

A mí no me gusta la rutina, no me gusta ese levantate a la mañana, hacé fuego, hacé tortilla, cociná, barré, ve los animales, levantate, hacé fuego [...] Mi evaluación, mi manera de verlo, lo que yo pienso en mí para adentro: ¿por qué tengo que estar aquí nomás, por qué no voy a disfrutar con una compañera, no voy a salir a tomar mate, si el día de mañana no me llevo nada? ¿No es lo más lindo los valores que tengamos o ayudar alguien, o simplemente tomar mate? A mí eso es lo que me gusta. No sé, pero por lo menos ando. 


\section{El descubrimiento de "lo político" de la vida íntima}

\section{Noelia}

En la historia de Noelia, aunque con un tratamiento más breve en este escrito, también se observan las motivaciones afectivas de la participación política, del fortalecimiento subjetivo de las mujeres como producto de la experiencia colectiva y de la resignificación de los espacios a ser ocupados según los roles de género, así como la construcción de sentidos alternativos como móviles para la vida. En el caso de Noelia, la particularidad es que proviene de una familia de productores campesinos que, si bien pertenecen al mismo territorio, contaban con algunas pequeñas ventajas económicas con respecto a la población contigua, debido a que, por herencia, tenían más animales que destinaban a la venta. De acuerdo con sus memorias, "vivía bien, nunca me faltaba qué comer o una ropa más linda para ponerme”. Por ello su infancia transcurrió más tranquilamente: ni ella ni su familia debieron trabajar para patrones y pudo terminar la escuela primaria en un poblado cercano. Actualmente, construye la narrativa de su vida a partir de un antes y un después, puesto que tras su casamiento y participación en la organización accedió a “una vida más humilde”, pero que representó una ganancia porque conoció “otros mundos” y no añora "lo chiquita” que era su vida antes. Con ello hace referencia a un modo de vida previo con fronteras de sociabilidad $y$ afecto delimitadas por el modelo de familia nuclear y, posteriormente, el descubrimiento de una nueva forma centrada en los vínculos comunitarios.

Noelia se casó a los diecinueve años con un hombre de una familia más humilde a expensas del rechazo de su familia de nacimiento, y se mudó junto a su marido y el padre de él, que era una figura histórica de la organización, reconocido hoy como un "anciano sabio" y como uno de los fundadores del movimiento ${ }^{16}$. Ella recuerda con mucha emoción a este hombre ya fallecido y a su esposa como "segundos padres”, con quienes vivió una “segunda adolescencia” y generó lazos afectivos de mucha proximidad:

$\mathrm{N}$ : Me parecía importante porque mis padres, los que me criaron, nunca me hablaron de la solidaridad que teníamos que tener con el vecino. Mis padres eran diferentes; ellos eran ellos, su familiar, su hijo, su hija, 
y ellos y nada más [...] Y yo empezaba a mirar, me parecía que era otro mundo y que yo en ese camino tenía que estar. Que ese era mi camino. A: ¿Y en qué cree que el movimiento le cambió?

$\mathrm{N}$ : Me cambió de hacerme conocer otro mundo. Porque a mí no me gustaba esa vida que uno vivía vos y nada más [...] Entré en una vida más humilde, pero era un orgullo para mí porque he aprendido un montón de otras cosas. Porque uno tiene que ver a veces los dos mundos para volver a creer las cosas.

Si bien en este relato la figura de referencia aparece exaltada y la propia vida de Noelia resulta cargada de mística, aquí no nos ocupa la objetividad de los hechos históricos, sino los sentidos que ella construye. En sus recuerdos también se reitera que, en la etapa anterior, los roles de género se demarcaban tradicionalmente y de forma asimétrica, una condición que actualmente cuestiona:

A: ¿Y su madre, por ejemplo, hacía todo adentro de la casa?

$\mathrm{N}$ : También, así. Y ella nos enseñaba que la ropa de los hermanos tiene que estar preparada cuando vengan a bañarse. Nos hacía eso, ¿entendés? Las mujeres tenían que lavarle la ropa, plancharles, ponerle en la percha. La gente de antes era muy machista, que simplemente el hombre era para que vaya afuera a hacer trabajo y la mujer se quede en su casa nada más cuidando los hijos, que tiene que atenderlo al hombre cuando viene de afuera, del trabajo. El hombre en la casa no tenía que hacer nada.

Por ello destaca las influencias del trabajo político de su suegro (también en el fortalecimiento de la participación femenina) en el cambio de su percepción en torno a las relaciones de género:

Yo le preguntaba y él decía: "La mujer también tiene su derecho igual que el hombre porque también sabe pensar, y también sabe opinar, y también sabe administrar”. Él hablaba siempre de la mujer. Cuando no había mujeres en las reuniones, cuando hacía reuniones de base o cuando estaba en una casa de familia - a veces iba a las casas a tomar mate y charlar con las familias, así como lo estás haciendo vos-, y a veces estaban los hombres de la casa, no estaba la mujer. [...] Él observaba si el hombre estaba sentado ahí conversando y la mujer allá cebaba mate por la cocina. Tampoco se sentaba así a cebar mate, de allá de la cocina traía el mate cebado y le servía a la visita y al marido, a los hijos mayores. Y él las llamaba a ellas, "venga usted también, vamos a charlar porque aquí está su esposo y usted también tiene que escuchar, porque yo estoy hablando con su esposo, usted también tiene derecho de saber". [...] Él también lo regañaba a mi marido: "Vaya usted, caliente el agua y traiga, vamos a tomar mate" o "levante usted el fuego para calentar el agua”. 
Actualmente, Noelia forma parte del área de salud, se ocupa de la articulación con las organizaciones nacionales e internacionales (CLOC o Vía Campesina, entre otras) y participa en las agendas de salud y género de la organización. A raíz de ello ha estado en encuentros y convivencias con otros movimientos campesinos, como el MST o el EZLN, y vive en la comunidad de base en la que fui recibida durante la investigación.

\section{A modo de conclusión}

Este artículo aporta a la discusión sobre el impacto de la participación política de mujeres en movimientos sociales rurales; en este caso, a partir del Movimiento Campesino de Santiago del Estero-Vía Campesina, una organización que incorpora consignas de género pero no se reconoce como feminista. Estudios previos en otros contextos similares señalan que, a pesar de que en el discurso pueden presentarse nuevas perspectivas, en las prácticas cotidianas las mujeres hallan pocas posibilidades de revertir posiciones subjetivas ancladas en el ordenamiento tradicional de los géneros. Estas investigaciones insisten en que los movimientos sociales únicamente femeninos, o donde hay espacios exclusivos para las reivindicaciones de las mujeres, propician condiciones más favorables para dichas transformaciones.

Sin desestimar estas consideraciones, aquí propusimos una aproximación alternativa partiendo de relatos de vida de mujeres que son militantes históricas del movimiento, como complemento del trabajo etnográfico, para incorporar el carácter retrospectivo, longitudinal y subjetivo de las narrativas personales. Encontramos que esta técnica, destacada también en los estudios feministas, nos ha permitido acercarnos a ciertos intersticios que emergen al hacer evidentes los puntos de vista particulares, y desde allí reconstruir los significados colectivos. Ratificamos la importancia de rescatar las narrativas desde las voces de las mujeres para deconstruir los sesgos de una visión del mundo que se pretende neutral pero parte de una perspectiva masculina. A su vez, creemos que la dimensión afectiva incluida en el análisis enriquece el estudio de las motivaciones para la participación política, al reflejar deseos, estímulos y móviles individuales que exceden las explicaciones basadas en el interés racional.

En el caso de las mujeres militantes del Mocase-VC con quienes hemos trabajado, encontramos que el sentimiento de formar parte de un sector campesino explotado, unido al anhelo por participar en la vida política para revertir dichas injusticias y a las influencias de figuras de referencia, ocupan un lugar 
fundamental como alicientes para su integración en el movimiento. Luego, observamos un proceso de construcción subjetiva, a partir de la interiorización de sentidos, imaginarios e identidades colectivas que han contribuido al fortalecimiento de las mujeres de cara a sus intereses y a la reconfiguración de los roles asignados de acuerdo con el género. Es importante destacar en estas trayectorias de vida el componente emocional de las experiencias colectivas - cuya dimensión solidaria es un rasgo distintivo en la creación de la identidad del movimiento y de sus formas de protesta- que no había sido explorado desde el punto de vista del género. Estas vivencias generan sentimientos de gratificación y de dignidad y construyen lealtades afectivas que potencian las posibilidades de las mujeres de subvertir situaciones personales y posicionamientos subjetivos subordinados.

De ningún modo estas reflexiones pretenden sugerir un universo idealizado en el que se ha alcanzado la igualdad entre los sexos. Por el contrario, como parte de la perspectiva feminista en la cual se inscribe el trabajo, se asume que los patrones culturales que ubican la condición femenina en un lugar subalterno forman parte de la vida social contemporánea en cualquier ámbito que analicemos. Además, todos los procesos políticos tienen sus propias limitaciones. Sin embargo, consideramos relevante señalar las trayectorias colectivas de resistencia y de creación de ciertas condiciones para alterar, o al menos matizar, las relaciones de poder basadas en el género y hacemos un llamado a la producción de futuras investigaciones que profundicen este debate.

\section{Referencias}

Acker, Joan. 1990. "Hierarchies, Jobs, Bodies: A Theory of Gendered Organizations”. Gender and Society 4 (2): 139-158.

Acosta, Yennisey Valles y José María Bonfiglio. 2014. "Mujeres y acción colectiva para la regularización de la tierra: un caso de Monterrey, México". Revista Estudos Feministas 3 (22): 863-884.

Atkinson, Robert. 1998. The Life Story Interview. Londres: Sage Publications.

Barbetta, Pablo. 2009. "En los bordes de lo jurídico: conflictos por la tenencia legal de la tierra en Santiago del Estero”. Tesis de doctorado, Universidad de Buenos Aires.

Barbieri, Teresita de. 1998. “Acerca de las propuestas metodológicas feministas”. En Debates en torno a una metodología feminista, compilado por Eli Bartra, 103-140. Ciudad de México: Universidad Autónoma Metropolitana.

Bertaux, Daniel. (1980) 1999. "El enfoque biográfico, su validez metodológica, sus potencialidades”. Traducido por el TCU 0113020 de la Universidad de Costa Rica. Proposiciones 29: 1-22. 
Brumer, Anita. 2004. "Gênero e agricultura: a situação da mulher na agricultura do Rio Grande do Sul”. Revista Estudos Feministas 12 (1): 205-227.

Carneiro, María José. 1994. "Mulheres no campo: notas sobre sua participação política e a condição social do gênero”. Estudos Sociedade e Agricultura 2: 11-22.

Da Silva, Cristiani Bereta. 2004. "Relações de gênero e subjetividades no devir MST”. Revista Estudos Feministas 12 (1): 269-287.

Dargoltz, Raúl. 1997. “El movimiento campesino santiagueño-Mocase”. Revista Taller 2 (4): 27-32.

De Dios, Rubén. 2009. "Los campesinos santiagueños y su lucha por una sociedad diferente”. Ponencia presentada en el I Congreso Nacional de Protesta Social, Acción Colectiva y Movimientos Sociales, Buenos Aires, 30 y 31 de marzo del 2009. http://www.iade.org.ar/ uploads/beaee573-e871-0024.pdf.

Di Liscia, María Herminia. 2007. “Género y memorias”. La Aljaba 1: 141-166.

Díaz Estévez, Pablo. 2005. "Resistencia campesina en Santiago del Estero". Informe final del concurso Poder y Nuevas Experiencias Democráticas en América Latina y el Caribe. Programa Regional de Becas Clacso. http://biblioteca.clacso.edu.ar/ar/libros/becas/2005/ demojov/diaz.pdf.

Durand, Patricia. 2006. "Desarrollo rural y organización campesina en Argentina. El caso del Movimiento Campesino de Santiago del Estero”. Tesis de doctorado, Universidad de Buenos Aires.

Ferrante, Vera Lucía, Henrique Carmona Duval, Sonia Maria Pessoa Pereira Bergamasco y Ana Paula Fraga Bolfe. 2013. "Na trajetória dos assentamentos rurais: mulheres, organização e diversificação". En Mulheres camponesas: trabalho produtivo e engajamentos políticos, organizado por Delma Neves y Leonilde Servolo de Medeiros, 195-216. Niteroi: Alternativa.

Furlin, Neiva. 2013. "A perspectiva de gênero no MST: um estudo sobre o discurso e as práticas de participação das mulheres”. En Mulheres camponesas: trabalho produtivo e engajamentos políticos, organizado por Delma Neves y Leonilde Servolo de Medeiros, 257-282. Niteroi: Alternativa.

Giarraca, Norma. 2001. "El 'Movimiento de Mujeres Agropecuarias en Lucha': protesta agraria y género durante el último lustro en Argentina”. En ¿Una nueva ruralidad en América Latina?, compilado por Norma Giarraca, 129-151. Buenos Aires: Clacso.

Gómez, Raimundo, Raúl Ithuralde y Marcelo Otero. 2011. Raimundo Gómez: caminante de los bosques. Santiago del Estero: Mocase-Vía Campesina.

Guber, Rosana. 2011. La etnografía. Método, campo y reflexividad. Buenos Aires: Siglo XXI.

Jasper, James. 2012. "Las emociones y los movimientos sociales: veinte años de teoría e investigación”. Revista Latinoamericana de Estudios sobre Cuerpos, Emociones y Sociedad 4 (10): 46-66.

Lamas, Marta. 1999. “Género, diferencias de sexo y diferencia sexual”. Debate Feminista 20: 84-106.

Lechat, Noélle Marie. 1993. “A questão de gênero no Movimento dos Trabalhadores Rurais Sem Terra (MST): estudo de dois assentamentos no Rio Grande do Sul”. Tesis de Maestría en Antropología, Universidad Estadual de Campinas. 
Melucci, Alberto. 1996. Challenging Codes: Collective Action in the Information Age. Cambridge: Cambridge University Press.

Michi, Norma. 2010. Movimientos campesinos y educación. El Movimiento Sin Tierra y el Movimiento Campesino de Santiago del Estero-VC. Buenos Aires: El Colectivo.

Mies, María. 1998. “¿Investigación sobre las mujeres o investigación feminista? El debate en torno a la ciencia y la metodología feminista”. En Debates en torno a una metodología feminista, compilado por Eli Bartra, traducido por Gloria Elena Bernal, 63-102. Ciudad de México: Universidad Autónoma Metropolitana de México.

Murillo, Soledad. 1996. El mito de la vida privada. Madrid: Siglo XXI.

Palacios Sepúlveda, Fernanda. 2011. “La siembra feminista de la Vía Campesina”. Tesis de Maestría en Estudios Feministas, Universidad Complutense de Madrid.

Paulilo, María Ignes. 2009. "Movimentos das mulheres agricultoras e os muitos sentidos da 'igualdade de gênero'”. Em Lutas camponesas contemporâneas: condições, dilemas e conquistas: a diversidade das formas das lutas no campo, organizado por Bernardo Fernandes, Leonilde Servolo de Medeiros, Maria Ignez Paulilo, 179-202. São Paulo: Edunesp.

-. 2004. "O peso do trabalho leve”. Ciência Hoje 5 (28): 64-70.

Paván, Dulcinea. 1998. “As Marias Sem-Terra: trajetórias e experiências de vida de mulheres assentadas em Promissão/SP 1985-1996”. Tesis de Maestría en Historia, Pontifícia Universidade Católica de São Paulo.

Pinto, Celi. 1992. "Movimentos sociais: espaços privilegiados da mulher enquanto sujeito político”. En Uma questão de gênero, organizado por Albertina de Oliveira Costa y Cristina Bruschini, 127-150. Río de Janeiro y São Paulo: Rosa dos Ventos y Fundação Carlos Chagas.

Pujadas, Juan José. 2000. "El método biográfico y los géneros de la memoria”. Revista de Antropología Social 9: 127-158.

Rubin, Jeffrey. 1998. “Ambiguity and Contradiction in a Radical Popular Movement”. En Cultures of Politics / Politics of Cultures: Re-visioning Latin American Social Movements, editado por Sonia Álvarez, Evelina Dagnino y Arturo Escobar, 141-164. Boulder, CO: Westview Press.

Salvaro, Giovana Ilka Jacinto, Mara Coelho de Souza Lago y Cristina Scheibe Wolff. 2014. "Limites e possibilidades da militância política em um movimento social rural de mulheres”. Revista Estudos Feministas 22 (1): 51-70.

Scott, Joan. 2001. “La querelle des femmes’ no final do século XX”. Revista Estudos Feministas 9 (2): 367-388.

-. (1990) 1996. "El género: una categoría útil para el análisis histórico”. En El género: la construcción cultural de la diferencia sexual, compilado por Marta Lamas, 265-302. Ciudad de México: PUEG.

Segalén, Martine. 1992. Antropología histórica de la familia. Madrid: Taurus.

Teixeira, Zuleide, coord. 1994. Perspectiva de gênero na produção rural. Brasilia: IPEA.

Wacheux, Frédéric. 1996. Méthodes qualitatives et recherche en gestion. París: Économica.

Woortmann, Klass. 1990. “'Com parente não se neguceia’: o campesinato como ordem moral”. Anuário Antropológico 87: 11-73. 